\title{
Low concentration continuous femoral nerve block improves analgesia and functional outcomes after total knee arthroplasty in spinal anesthesia
}

Received January 23, 2018

Revised 1st, May 15, 2018

2nd, June 12, 2018

3rd, June 19, 2018

Accepted July 4, 2018

\section{Corresponding author}

Yun Suk Choi, M.D., Ph.D. Department of Anesthesiology and Pain Medicine, Jeju National University Hospital, Jeju National University School of Medicine, 15 Aran 13-gil, Jeju 63241, Korea Tel: 82-64-717-2025

Fax: 82-64-717-2042

E-mail: solafide5@yahoo.co.kr ORCID

http://orcid.org/0000-0002-7983-8089

\section{So Hui Yun ${ }^{1}$, Yun Suk Choi' , and Sang Rim Kim²}

${ }^{1}$ Department of Anesthesiology and Pain Medicine, Jeju National University Hospital, Jeju National University School of Medicine, ${ }^{2}$ Department of Orthopedic Surgery, Jeju National University Hospital, Jeju, Korea

Background: Total knee arthroplasty (TKA) is associated with severe pain postoperatively. Femoral nerve block is commonly used for pain control after TKA. This study investigated whether continuous femoral nerve block (CFNB) can improve postoperative analgesia and functional outcome as compared to intravenous patient controlled analgesia (PCA) in patients with TKA.

Methods: We reviewed the electronic medical records of patients who underwent TKA with spinal anesthesia between March 2014 and February 2015. In Group IV, postoperative pain was managed by IV-PCA. Group CFNB received CFNB-PCA via a device. Thirty patients were enrolled per group. Patient outcomes were assessed by analgesia, functional outcomes, and health-related quality of life factors.

Results: Additional analgesics and additional nerve block for adequate pain control were significantly more frequent in the IV than CFNB group $(P=0.015$ and $P=0.012$, respectively). Range of motion up to 105 degrees was prolonged in the IV group than CFNB group ( $P=0.013$ ). EuroQol five dimensions score was improved in the CFNB group than IV group postoperative 3 weeks $(P=0.003)$. The incidence of transfusion due to postoperative bleeding was significantly frequent in the IV group than CFNB group ( $P=$ 0.042).

Conclusions: Postoperative low concentration continuous femoral nerve block for analgesia after TKA improves analgesia, functional outcomes, and incidence of transfusion without falling risk.

Keywords: Blood transfusion; Femoral nerve; Knee replacement arthroplasty; Nerve block; Patient-controlled analgesia; Patient outcome assessments.

\section{INTRODUCTION}

Total knee arthroplasty (TKA) is a frequently performed elective orthopedic intervention for painful arthritic knees. However, TKA is followed by intense postoperative pain. Yet, early mobilization post-TKA can prevent knee stiffness, lessen hospital stay, and improve overall patient satisfaction [1-4]. Also early mobilization is associated with a decreased risk of deep vein thrombosis and good functional outcomes $[5,6]$. Therefore, appropriate pain control after TKA is important. An ideal analgesic modality for post-TKA rehabilitation should permit adequate knee flexion with minimal pain and

This is an Open Access article distributed under the terms of the Creative Commons Attribution Non-Commercial License (http://creativecommons.org/licenses/by-nc/4.0) which permits unrestricted non-commercial use, distribution, and reproduction in any medium, provided the original work is properly cited. 
without motor impairment, resulting in successful mobilization [7]. Conventional postoperative analgesia is provided by IV-patient controlled analgesia (PCA). Continuous femoral nerve block (CFNB) with local anesthetics has been consistently shown to provide superior analgesia and less sideeffects compared with systemic opioids, thus facilitating exercises to increase the degree of knee flexion $[2,8]$.

This study was designed to compare the quality of analgesia offered by CFNB and conventional intravenous PCA and their impact on ambulatory ability and functional performance in both the postoperative period and 4 weeks after surgery. Additionally, we evaluated whether continuous femoral nerve block could related with incidence of transfusion.

\section{MATERIALS AND METHODS}

This study was approved by the Institutional Review Board of the Jeju National University Hospital (IRB no. 2015-02008).

\section{Patient population}

We reviewed the electronic medical records of patients who had undergone TKA with spinal anesthesia between March 2014 and February 2015. Patients with severe cardiac disease, advanced heart block, severe coronary artery disease, aberrant renal or hepatic function, mental retardation, patients who were already hypotensive and/or hypovolemic, underwent revision surgery after previous ipsilateral operation, bilateral TKA, who had missing data, or were lost to follow-up during rehabilitation, were excluded.

\section{Group assessment}

Postoperative pain was managed using an IV-PCA device containing $10 \mu \mathrm{g} / \mathrm{kg}$ fentanyl, $300 \mathrm{mg}$ ketorolac, and $0.3 \mathrm{mg}$ ramosetron mixed in normal saline in a total volume of 100 $\mathrm{ml}$ (delivered at a basal rate of $1 \mathrm{ml} / \mathrm{h}, 1 \mathrm{ml}$ bolus, and with a lockout-time of 15 minutes) in Group IV. In Group CFNB, CFNB was administered via a device containing $250 \mathrm{ml}$ of $0.5 \%$ lidocaine (delivered at a basal rate of $3 \mathrm{ml} / \mathrm{h}, 3 \mathrm{ml}$ bolus, and with a lockout-time of 30 minutes). Thirty patients were enrolled in each group. The use of this PCA began with access to the recovery room.

\section{Anesthetic regimen}

All patients were admitted to the operating room without premedication; they underwent noninvasive blood pressure monitoring, electrocardiography, and pulse oximetry. After measuring the initial vital signs, Ringer's lactate solution and oxygen were administered. Spinal anesthesia was induced at L4-L5 or L3-L4 intervertebral spaces, using 810 mg bupivacaine $\mathrm{HCl}$ (AstraZeneca, Australia). Surgery was started when a bilateral sensory blockade was achieved up to the T10 dermatome. Additional sedative (midazolam, 2-5 mg) was used during surgery.

In Group CFNB, catheterization was applied prior to surgery using a 18-G stimulating Touhy needle (StimuLong NanoLine, Germany) under ultrasound-guidance (Philips Ultrasound Inc., Sanmina-SCI Systems Singapore Pts Ltd., USA). Identification of a persistent rhythmic contraction of the quadriceps muscle (also described as a "patellar snap") was sought at a diminished nerve stimulator (Stimulplex-DIG RC, B. Braun Melsungen AG, Germany) output to $0.5 \mathrm{~mA}$.

\section{Postoperative care}

Postoperative pain was assessed using the visual analogue scale; when the score was 5 or more, adjunct analgesics (tramadol $50 \mathrm{mg}$ or pethidine $25 \mathrm{mg}$ ) was administered intravenously in the ward. Indications for blood transfusion included hemoglobin $<9 \mathrm{mg} / \mathrm{dl}$ or $9 \leq$ hemoglobin $<11 \mathrm{mg} /$ $\mathrm{dl}$ associated with tachycardia, hypotension, or dizziness.

In general, patients receiving continuous passive motion (CPM) treatment increased their range of motion by $15^{\circ}$ in 1 day, starting at $30^{\circ}$ in the first 2 postoperative days. Ambulation exercise, using a walker, was started on the 3rd postoperative days after the PCA was removed. Patients who could not progress in CPM due to severe knee pain during exercise periods were referred to the pain clinic and underwent an additional single injection of femoral nerve block with $15 \mathrm{ml}$ of $0.2 \%$ ropivacaine. Rehabilitation was continues, and functional outcomes were assessed at 2 and 4 weeks postoperatively. 


\section{Outcome measures}

\section{Analgesia}

The quality of postoperative analgesic effect was estimated by the incidence of injected additional analgesics and additional nerve block. The incidence of the injected additional analgesics was measured for adequate pain control during the PCA infusion period, while that of the additional nerve block was measured by consultation at a pain clinic for adequate pain control with additional nerve block after suspension of PCA to 2 weeks postoperatively.

\section{Functional outcomes}

Assessment of knee function: In order to evaluate the selfreported functional status, the Western Ontario and Mc Master Universities Osteoarthritis Index (WOMAC) questionnaire was used as a subjective index [9]. The CPM angle was measured by objective index. Measurements of knee joint motion range for flexion and extension of the active knee in all patients were accurately measured by goniometer.

Assessment of ambulatory ability: The Berg's balance scale (BBS) is used to objectively determine a patient's ability to functional balance during a series of predetermined tasks [10]. It is a 14 item list such as ranging from standing up from a sitting position, to standing on tone foot with each item consisting of a five-point ordinal scale ranging from 0 (lowest level) to 4 (highest level). To evaluate the dynamic balance ability, Timed Up and Go (TUG) test was performed [11]. It uses the time that a patient takes to rise from a chair, walk 3 meters, turn around, walk back to the chair, and sit down. The TUG test is used frequently in the elderly population, as it is easy to administer and can generally be completed by most older adults [12]. 10 Meter Walk Test (10MWT) assesses walking speed in meters per second over a short duration. It can be employed to determine functional mobility, gait, and vestibular function.

\section{Health-related quality of life}

All patients were assessed for their health-related quality of life by using the EuroQol five dimensions (EQ5D) questionnaire. This index comprehensively evaluates the five dimensions of health factors: athletic ability, self-care, daily activities, pain and discomfort, anxiety and depression. As a result, the value of each factor closer to 1 means healthier.

\section{Data collection}

One individual retrospectively reviewed the electronic medical records. These records provided all the data required for analysis.

Surgery, tourniquet, and anesthesia time were made based on review of the information recorded in the anesthesia record form. Assessment of side effect (nausea, vomiting, and dizziness) and incidence of transfusion occurring after postoperative PCA was made based on review of information recorded in the nursing chart. Assessment of knee function was evaluated using the daily CPM and WOMAC score at 3 weeks and 3 months postoperatively. Assessment of functional outcome was evaluated using the BBS, the TUG test, and the 10MWT at 2 and 4 weeks postoperatively. Assessment of health-related outcome was evaluated using EQ5D at preoperatively and 3 weeks postoperatively. Functional outcomes and EQ5D assessment were surveyed in the rehabilitation records.

\section{Statistical analysis}

Statistical analyses were performed using STATA (StataCorp., USA). Data were reported as mean \pm SD for continuous variables, and percentages for quantitative variables. ANOVA, chi-squared test, or Fisher's exact test were used, as appropriate for continuous or categorical variables. $\mathrm{P}$ values less than 0.05 were considered to indicate statistical significance.

Rescue analgesics for postoperative pain control was the primary outcome variable on which sample size estimation was based. A previous study found that opioid consumption was $13.5 \pm 7.8 \mathrm{mg}$ on postoperative 48 hours [13]. The sample size calculation for this study showed that a total of 28 patients were needed when we considered a type I $(\alpha)$ error to be 0.05 , type II ( $\beta$ ) error to be 0.20 , an $\mathrm{SD}=7.8$, and the predicted dropout rate to be $10 \%$.

\section{RESULTS}

Patient demographics are shown in Table 1. More than $80 \%$ of patients were female, and the mean age of patients was over 70 years.

Postoperative side effects of PCA, such as nausea and vomiting, were not significantly different between the groups. Diz- 
Table 1. Demographic and Perioperative Data

\begin{tabular}{lccc}
\hline \multicolumn{1}{c}{ Variable } & Group IV $(\mathrm{n}=30)$ & Group CFNB $(\mathrm{n}=30)$ & P value \\
\hline Gender & & $5(16.7)$ & 1.000 \\
Male & $4(13.3)$ & $25(83.3)$ \\
Female & $26(86.7)$ & $74.9 \pm 5.0$ \\
Age $(\mathrm{yr})$ & $73.1 \pm 6.0$ & $152.8 \pm 6.0$ & 0.195 \\
Height $(\mathrm{cm})$ & $153.5 \pm 6.6$ & $62.0 \pm 8.1$ & 0.683 \\
Weight (kg) & $61.6 \pm 11.0$ & $26.5 \pm 3.4$ & 0.873 \\
BMI & $26.0 \pm 3.6$ & $19(63.3)$ & 0.585 \\
HTN & $24(80.0)$ & $1(3.3)$ & 0.252 \\
DM & $6(20.0)$ & $0(0)$ & 0.103 \\
CVA & $2(6.7)$ & $75.6(72.9-78.2)$ & 0.492 \\
Surgery time (min) & $75.8(72.7-78.9)$ & $43.3(41.8-45.1)$ \\
Tourniquet time (min) & $41.4(39.6-43.2)$ & $108.3(104.8-111.7)$ \\
Anesthetic time (min) & $112.9(109.1-116.8)$ & 0.906 \\
\hline
\end{tabular}

Data are presented as number (\%), mean \pm SD or mean (95\% confidence interval). Group IV: patient controlled analgesia by intravenous approach, Group CFNB: patient controlled analgesia by continuous femoral nerve block approach. BMl: body mass index, HTN: hypertension, DM: diabetes mellitus, CVA: cerebrovascular accident.

ziness was more frequently in group IV (5 patients, $16.7 \%)$, but this was not statistically significant $(\mathrm{P}=0.052)$ (Table 2$)$. The incidence of additional analgesic administration was significantly higher in group IV (16 patients, 53.3\%) than in group CFNB (6 patients, 20.0\%) during use of PCA ( $\mathrm{P}=0.015)$. Incidence of additional nerve block for adequate pain control during CPM period was higher in group IV (9 patients, 30.0\%) than in group CFNB (1 patient, 3.3\%) $(\mathrm{P}=0.012)$. Furthermore, in group IV, incidence of transfusion due to postoperative bleeding significantly more frequently than group CFNB $(\mathrm{P}=0.042)$.

Up to $90^{\circ}$ in CPM, there was no significant difference between the two groups. However, advancement of CPM to $105^{\circ}$ took longer in group IV than in group CFNB $(\mathrm{P}=0.013)$ (Table 3). There was no significant difference in the functional outcome assessment at 2 and 4 weeks postoperatively (Table 4). The EQ5D index values did not differ significantly between the two groups before surgery, but were significantly lower in group CFNB than in group IV at 3 weeks postoperatively $(\mathrm{P}=0.003)$ (Table 4).

\section{DISCUSSION}

In this study, we found that CFNB was more effective for pain control, reducing the incidence of blood transfusion, and improving the health-related quality of life outcome (EQ5D) than was conventional IV-PCA. CFNB also made an ordinarily increase in the angle of $\mathrm{CPM}$ over $90^{\circ}$ during reha-
Table 2. Management of Patients in Postoperative Period

\begin{tabular}{lrll}
\hline \multicolumn{1}{c}{ Variable } & $\begin{array}{c}\text { Group IV } \\
(\mathrm{n}=30)\end{array}$ & $\begin{array}{c}\text { Group CFNB } \\
(\mathrm{n}=30)\end{array}$ & P value \\
\hline Side effect of PCA & & & \\
$\quad$ Nausea & $9(30.0)$ & $9(30.0)$ & 1.000 \\
Vomiting & $3(10.0)$ & $3(10.0)$ & 1.000 \\
Dizziness & $5(16.7)$ & $0(0)$ & 0.052 \\
Additional analgesics & $16(53.3)$ & $6(20.0)$ & 0.015 \\
Additional nerve block & $9(30.0)$ & $1(3.3)$ & 0.012 \\
Transfusion & $9(30.0)$ & $2(6.7)$ & 0.042
\end{tabular}

Data are presented as number (\%). Group IV: patient controlled analgesia by intravenous approach, Group CFNB: patient controlled analgesia by femoral nerve block approach. PCA: patient controlled analgesia, Additional analgesics: incidence of additional analgesics for adequate pain control except during PCA infusion period, Additional nerve block: incidence of consultation at pain clinic for adequate pain control with additional nerve block from suspension of PCA to 2 weeks postoperatively.

bilitation physiotherapy possible. However, the occurrence of side effect of PCA and the patients' functional outcome were not significantly different between the two groups.

Severe pain after TKA has been associated with poor functional outcome [14-16]. Post-TKA pain has a direct impact on postoperative physiotherapy and mobilization, which can result in stiffness and poor joint function [1-3]. FNB is often considered as the gold standard for pain alleviation after TKA [8,17-19]. The effectiveness of CFNB in reducing pain postTKA as compared with intravenous PCA has been demonstrated previously $[2,8,20-22]$. We were compared patients with additional analgesics due to inadequate pain control 
Table 3. Postoperative Assessment of Functional Outcomes related to Knee Function

\begin{tabular}{|c|c|c|c|c|c|c|c|}
\hline \multirow{2}{*}{ Item } & \multirow{2}{*}{ Group } & \multirow{2}{*}{$\begin{array}{l}\text { Mean } \\
\text { (POD) }\end{array}$} & \multirow{2}{*}{ SD } & \multirow{2}{*}{ SEM } & \multicolumn{2}{|c|}{$95 \% \mathrm{Cl}$ of difference } & \multirow{2}{*}{ P value } \\
\hline & & & & & Lower & Upper & \\
\hline \multirow[t]{2}{*}{ СРМЗО } & IV & 2.00 & 0.00 & 0.00 & 2.00 & 2.00 & 0.322 \\
\hline & CFNB & 2.03 & 0.18 & 0.03 & 1.97 & 2.10 & \\
\hline \multirow[t]{2}{*}{ CPM60 } & IV & 4.00 & 0.00 & 0.00 & 4.00 & 4.00 & 0.322 \\
\hline & CFNB & 4.03 & 0.18 & 0.03 & 3.97 & 4.10 & \\
\hline \multirow[t]{2}{*}{ CPM90 } & IV & 6.70 & 0.92 & 0.17 & 6.36 & 7.04 & 0.883 \\
\hline & CFNB & 6.73 & 0.83 & 0.15 & 6.42 & 7.04 & \\
\hline \multirow[t]{2}{*}{ CPM105 } & IV & 9.87 & 1.46 & 0.27 & 9.32 & 10.41 & 0.013 \\
\hline & CFNB & 9.03 & 1.03 & 0.19 & 8.65 & 9.42 & \\
\hline \multirow[t]{2}{*}{ WOMAC-3W } & IV & 28.2 & 11.5 & 2.3 & 23.5 & 32.8 & 0.938 \\
\hline & CFNB & 27.9 & 14.7 & 3.2 & 21.2 & 34.5 & \\
\hline \multirow[t]{2}{*}{ WOMAC-3m } & IV & 14.6 & 7.2 & 2.4 & 9.0 & 20.1 & 0.054 \\
\hline & CFNB & 22.6 & 8.7 & 3.1 & 15.3 & 29.9 & \\
\hline
\end{tabular}

Group IV: patient controlled analgesia by intravenous approach, Group CFNB: patient controlled analgesia by femoral nerve block approach, POD: postoperative day, SEM: standard error of mean, $95 \% \mathrm{Cl}$ of difference: 95\% confidence interval of difference between means, CPM30: continuous passive motion from 0 to 30 degrees, CPM60: continuous passive motion from 30 to 60 degrees, CPM90: continuous passive motion from 60 to 90 degrees, CPM105: continuous passive motion from 90 to 105 degrees, WOMAC-3w: Western Ontario and Mc Master Universities Osteoarthritis Index at 3 weeks postoperatively, WOMAC-3m: Western Ontario and Mc Master Universities Osteoarthritis Index at 3 months postoperatively.

Table 4. Assessment of Functional Outcomes related to Ambulatory Ability and Survey on Quality of Life Index (EQ5D Index)

\begin{tabular}{|c|c|c|c|c|c|c|c|}
\hline \multirow{2}{*}{ Item } & \multirow{2}{*}{ Group } & \multirow{2}{*}{ Mean } & \multirow{2}{*}{ SD } & \multirow{2}{*}{ SEM } & \multicolumn{2}{|c|}{$95 \% \mathrm{Cl}$ of difference } & \multirow{2}{*}{ P value } \\
\hline & & & & & Lower & Upper & \\
\hline \multirow[t]{2}{*}{ BBS-2w } & IV & 50.2 & 6.2 & 1.1 & 47.8 & 52.5 & 0.859 \\
\hline & CFNB & 50.4 & 2.6 & 0.6 & 49.2 & 51.6 & \\
\hline \multirow[t]{2}{*}{ BBS-4w } & IV & 52.9 & 2.4 & 0.4 & 52.0 & 53.8 & 0.813 \\
\hline & CFNB & 53.1 & 2.0 & 0.4 & 52.2 & 53.9 & \\
\hline \multirow[t]{2}{*}{ TUGT-2w } & IV & 18.2 & 7.3 & 1.4 & 15.4 & 21.0 & 0.730 \\
\hline & CFNB & 19.0 & 8.2 & 1.8 & 15.2 & 22.7 & \\
\hline \multirow[t]{2}{*}{ TUGT-4w } & IV & 13.1 & 3.1 & 0.6 & 11.9 & 14.3 & 0.651 \\
\hline & CFNB & 13.6 & 4.4 & 1.0 & 11.5 & 15.7 & \\
\hline \multirow[t]{2}{*}{ 10MWT-2w } & IV & 15.9 & 4.4 & 0.8 & 14.3 & 17.6 & 0.399 \\
\hline & CFNB & 17.3 & 7.0 & 1.5 & 14.1 & 20.5 & \\
\hline \multirow[t]{2}{*}{ 10MWT-4w } & IV & 12.2 & 2.2 & 0.4 & 11.3 & 13.0 & 0.603 \\
\hline & CFNB & 12.7 & 4.5 & 1.0 & 10.5 & 14.8 & \\
\hline \multirow[t]{2}{*}{ EQ5D-0w } & IV & 10.4 & 1.3 & 0.3 & 9.9 & 10.9 & 0.611 \\
\hline & CFNB & 10.6 & 1.3 & 0.3 & 10.0 & 11.1 & \\
\hline \multirow[t]{2}{*}{ EQ5D-3w } & IV & 8.5 & 1.0 & 0.2 & 8.1 & 8.9 & 0.003 \\
\hline & CFNB & 7.3 & 1.6 & 0.3 & 6.6 & 8.0 & \\
\hline
\end{tabular}

EQ5D index: standardized instrument for use as a measure of health outcome (EuroQol five dimensions questionnaire), Group IV: patient controlled analgesia by intravenous approach, Group CFNB: patient controlled analgesia by femoral nerve block approach, SEM: standard error of mean, 95\% Cl of difference: 95\% confidence interval of difference between means, BBS: Berg's balance scale, TUGT: timed up and go test, $10 \mathrm{MWT:} 10$ meter walk test, 2w: postoperative 2 weeks, 3w: postoperative 3 weeks, 4w: postoperative 4 weeks, Ow: preoperatively.

during PCA injection for assess to analgesic effect. As a result, the IV group (16 patients, $53.3 \%$ ) was significantly more frequent administered additional analgesics than the CFNB group (6 patients, $20.0 \%$ ). This means that the pain control in the CFNB group was more appropriate.

However, FNB reduces quadriceps muscle strength, and can therefore potentially compromise postoperative mobi- lization. Furthermore, FNB is associated with higher risks of falls, due to quadriceps weakness after the block [23-25]. The incidence of development of motor blockade by ropivacaine is concentration dependent, and most studies regarding the CFNB after TKA used $0.2 \%$ to $0.3 \%$ ropivacaine [26]. We were used $0.5 \%$ low dose lidocaine for reducing fall down risk. In this study, no patient experienced any falls or slips, and still 
adequate pain control was maintained. This lack of effect on motor power may be due to dilution of the concentration of the local anesthetic $(0.5 \%$ lidocaine infused $3 \mathrm{ml} / \mathrm{h})$. Thus, these low doses may be adequate analgesic effect, but may be related to the no significant difference in other function outcomes except CPM angle.

CPM rehabilitation physiotherapy findings were not significantly different between the two groups at a range of movement of less than $90^{\circ}$. But, it took a longer time for patients in group IV to read this angle in CPM. Furthermore, references to the pain clinic for additional single injection FNB during this period were significantly more in group IV than in group CFNB. Therefore, without additional nerve block during this period, the time to increase the CPM angle may have been further delayed.

EQ5D is a standardized measure of health status developed by the EuroQol Group in order to provide a simple, generic measure of health for clinical and economic appraisal. This index comprehensively evaluates the five dimensions of health factors. We were used this as an index for assessment of health-related outcome and prepared a preoperative and evaluated postoperative 3 weeks. According to the evaluation performed 3 weeks postoperatively, health outcome was significant improved measuring health related quality of life compared with preoperative status. However, functional outcome assessments showed no significant differences between the groups (Table 4). Based on these results, there is no difference in the functional outcome of the patients, but it can be considered that the feeling of discomfort felt by the patients themselves is significantly reduced.

According to a previous study, postoperative pain significantly influences postoperative blood loss in patients undergoing TKA [27]. The appropriate pain control is related with postoperative bleeding would have reduced the incidence of transfusion. Chelly et al. [20] reported that the use of continuous femoral infusion was associated with a significant reduction in postoperative blood loss and requirement for postoperative blood transfusions. The findings of this study cannot be clearly confirmed, as the records did not account for the amount of blood lost. However, the incidence of blood transfusion was significantly lower in group CFNB than in group IV. These results may indicate a related effect of CFNB on postoperative bleeding reduction.

Systemic opioid are associated with side effects, such as vomiting, constipation, mental slowing, postoperative cognitive dysfunction (particularly in the elderly patients), respiratory depression $[20,28]$ but FNB has been reported to decrease these side effects [29]. No significant difference was found in side effects between the two groups in the present study, which used a small amount of opioid (fentanyl $10 \mu \mathrm{g} /$ $\mathrm{kg}$ ) in group IV. These results could be considered as a side effect caused by a local anesthetic agent even though the amount of continuous infusion lidocaine is small or the temporary volume depletion after surgery, especially since the subject of study was an elderly patient. Instead, additional analgesics were administered for the appropriate pain control in group IV.

Our study had several limitations. The patients were not randomized, the sample size of the groups was small, and the data were collected retrospectively. The incidence of singleinjection FNB after TKA has been reported to decrease pain, facilitate rehabilitation, and reduce hospital length of stay as compared to conventional therapy [30]. However, we did not have data on the efficacy of CFNB as compared with another dose CFNB or single-injection FNB or other peripheral nerve blocks. In addition, we could not evaluate certain factors, such as the amount of postoperative bleeding that occurred, as these data were not recorded.

In conclusion, CFNB with a low concentration of postoperative analgesics after TKA improved the range of motion of patients, without resulting in falls, as well as the healthrelated quality of life as compared to IV-PCA. In addition, the incidence of blood transfusion was considered to be due to the beneficial effects of the postoperative pain control in elderly patients after TKA.

\section{ACKNOWLEDGMENTS}

This work was supported by a research grant from Jeju National University Hospital in 2017.

\section{REFERENCES}

1. Kehlet H. Surgical stress: the role of pain and analgesia. Br J Anaesth 1989; 63: 189-95.

2. Capdevila X, Barthelet Y, Biboulet P, Ryckwaert Y, Rubenovitch J, d'Athis F. Effects of perioperative analgesic technique on the surgical outcome and duration of rehabilitation after major knee 
surgery. Anesthesiology 1999; 91: 8-15.

3. Kehlet $\mathrm{H}$. The stress response to surgery: release mechanisms and the modifying effect of pain relief. Acta Chir Scand Suppl 1989; 550: 22-8.

4. Strassels SA, Chen C, Carr DB. Postoperative analgesia: economics, resource use, and patient satisfaction in an urban teaching hospital. Anesth Analg 2002; 94: 130-7.

5. Frassanito L, Vergari A, Zanghi F, Messina A, Bitondo M, Antonelli M. Post-operative analgesia following total knee arthroplasty: comparison of low-dose intrathecal morphine and singleshot ultrasound-guided femoral nerve block: a randomized, single blinded, controlled study. Eur Rev Med Pharmacol Sci 2010; 14: 589-96.

6. Ilfeld BM, Le LT, Meyer RS, Mariano ER, Vandenborne K, Duncan PW, et al. Ambulatory continuous femoral nerve blocks decrease time to discharge readiness after tricompartment total knee arthroplasty: a randomized, triple-masked, placebocontrolled study. Anesthesiology 2008; 108: 703-13.

7. Borgeat A. The role of regional anesthesia in patient outcome: orthopedic surgery. Tech Reg Anesth Pain Manag 2008; 12: 17882.

8. De Ruyter ML, Brueilly KE, Harrison BA, Greengrass RA, Putzke JD, Brodersen MP. A pilot study on continuous femoral perineural catheter for analgesia after total knee arthroplasty: the effect on physical rehabilitation and outcomes. J Arthroplasty 2006; 21 : 1111-7.

9. Bellamy N, Buchanan WW, Goldsmith CH, Campbell J, Stitt LW. Validation study of WOMAC: a health status instrument for measuring clinically important patient relevant outcomes to antirheumatic drug therapy in patients with osteoarthritis of the hip or knee. J Rheumatol 1988; 15: 1833-40.

10. Berg K, Wood-Dauphinee S, Williams JI. The Balance Scale: reliability assessment with elderly residents and patients with an acute stroke. Scand J Rehabil Med 1995; 27: 27-36.

11. Podsiadlo D, Richardson S. The timed "Up \& Go": a test of basic functional mobility for frail elderly persons. J Am Geriatr Soc 1991; 39: 142-8.

12. Yim-Chiplis PK, Talbot LA. Defining and measuring balance in adults. Biol Res Nurs 2000; 1: 321-31.

13. Shum CF, Lo NN, Yeo SJ, Yang KY, Chong HC, Yeo SN. Continuous femoral nerve block in total knee arthroplasty: immediate and two-year outcomes. J Arthroplasty 2009; 24: 204-9.

14. Williams-Russo P, Sharrock NE, Haas SB, Insall J, Windsor RE, Laskin RS, et al. Randomized trial of epidural versus general anesthesia: outcomes after primary total knee replacement. Clin Orthop Relat Res 1996; (331): 199-208.

15. Mahoney OM, Noble PC, Davidson J, Tullos HS. The effect of continuous epidural analgesia on postoperative pain, rehabilitation, and duration of hospitalization in total knee arthroplasty. Clin Orthop Relat Res 1990; (260): 30-7.

16. Fischer HB, Simanski CJ, Sharp C, Bonnet F, Camu F, Neugebauer EA, et al. A procedure-specific systematic review and consensus recommendations for postoperative analgesia following total knee arthroplasty. Anaesthesia 2008; 63: 1105-23.

17. Albrecht E, Morfey D, Chan V, Gandhi R, Koshkin A, Chin KJ, et al. Single-injection or continuous femoral nerve block for total knee arthroplasty? Clin Orthop Relat Res 2014; 472: 1384-93.

18. Paul JE, Arya A, Hurlburt L, Cheng J, Thabane L, Tidy A, et al. Femoral nerve block improves analgesia outcomes after total knee arthroplasty: a meta-analysis of randomized controlled trials. Anesthesiology 2010; 113: 1144-62.

19. Kim DH, Lin Y, Goytizolo EA, Kahn RL, Maalouf DB, Manohar A, et al. Adductor canal block versus femoral nerve block for total knee arthroplasty: a prospective, randomized, controlled trial. Anesthesiology 2014; 120: 540-50.

20. Chelly JE, Greger J, Gebhard R, Coupe K, Clyburn TA, Buckle R, et al. Continuous femoral blocks improve recovery and outcome of patients undergoing total knee arthroplasty. J Arthroplasty 2001; 16: 436-45.

21. Kadic L, Boonstra MC, DE Waal Malefijt MC, Lako SJ, VAN Egmond J, Driessen JJ. Continuous femoral nerve block after total knee arthroplasty? Acta Anaesthesiol Scand 2009; 53: 914-20.

22. Ilfeld BM, Meyer RS, Le LT, Mariano ER, Williams BA, Vandenborne $\mathrm{K}$, et al. Health-related quality of life after tricompartment knee arthroplasty with and without an extended-duration continuous femoral nerve block: a prospective, 1-year follow-up of a randomized, triple-masked, placebo-controlled study. Anesth Analg 2009; 108: 1320-5.

23. Feibel RJ, Dervin GF, Kim PR, Beaulé PE. Major complications associated with femoral nerve catheters for knee arthroplasty: a word of caution. J Arthroplasty 2009; 24: 132-7.

24. Ilfeld BM, Duke KB, Donohue MC. The association between lower extremity continuous peripheral nerve blocks and patient falls after knee and hip arthroplasty. Anesth Analg 2010; 111: 1552-4.

25. Sharma S, Iorio R, Specht LM, Davies-Lepie S, Healy WL. Complications of femoral nerve block for total knee arthroplasty. Clin Orthop Relat Res 2010; 468: 135-40.

26. Asakura Y, Yano T, Takagi H, Tsuchiya H, Kato T. The incidence of development of motor blockade by ropivacaine is concentration dependent, and most studies regarding the continuous FNB after total knee arthroplasty used $0.2 \%$ to $0.3 \%$ ropivacaine. J Arthroplasty 2010; 25: 836; author reply 837-8.

27. Guay J. Postoperative pain significantly influences postoperative 
blood loss in patients undergoing total knee replacement. Pain Med 2006; 7: 476-82.

28. Stone JG, Cozine KA, Wald A. Nocturnal oxygenation during patient-controlled analgesia. Anesth Analg 1999; 89: 104-10.

29. Park SJ, Shim SY, Park SG. A comparison of continuous femoral nerve block combined with sciatic nerve block and epidural analgesia for postoperative pain management after total knee replacement. Anesth Pain Med 2017; 12: 176-82.

30. Wang H, Boctor B, Verner J. The effect of single-injection femoral nerve block on rehabilitation and length of hospital stay after total knee replacement. Reg Anesth Pain Med 2002; 27: 139-44. 